\title{
Physicians' self-efficacy, beliefs and intentions to provide tobacco cessation services: A cross-sectional study in Riyadh, Saudi Arabia
}

\author{
Nervana Elkhadragy ${ }^{1}$, Sharon L. Christ ${ }^{2}$, Yara Bashawri ${ }^{3}$, Hadeel AlSaran ${ }^{3}$
}

\author{
AFFILIATION \\ 1 School of Pharmacy, University of Wyoming, Laramie, United States \\ 2 Purdue University, College of Health and Human Sciences, West \\ Lafayette, United States \\ 3 Research Center, King Fahad Medical City, Riyadh, Saudi Arabia
}

CORRESPONDENCE TO

Nervana Elkhadragy. School of Pharmacy, University of Wyoming, 1000 E University Ave, Laramie, WY 82071, United States. E-mail: nelkhadr@uwyo.edu

Popul. Med. 2021;3(April):10

\section{KEYWORDS}

physicians' beliefs, tobacco cessation services, smoking cessation, theory of reasoned action

Received: 27 October 2020, Revised: 18 March 2021, Accepted: 19 March 2021

https://doi.org/10.18332/popmed/134658

\begin{abstract}
INTRODUCTION Prevalence of tobacco use in the Kingdom of Saudi Arabia (KSA) is $12.2 \%$ and negatively impacting the health of the population. Diseases such as lung cancer, heart diseases, and poor prognosis of COVID-19 can be prevented by tobacco cessation. Physicians are trusted among patients and therefore are well-positioned to provide tobacco cessation services, however, their attitudes about such services are unknown. Our purpose is to assess attitudes about providing tobacco cessation services among physicians practicing in KSA.

METHODS This study is questionnaire-based and of crosssectional design. We applied the Theory of Reasoned Action (TRA) framework to guide our study. Twenty percent $(n=25)$ of primary care centers were randomly selected. A paperbased survey was administered to 291 physicians practicing in the selected primary care centers, each item mapped onto one of the seven TRA constructs. Constructs assessed were: demographics, self-efficacy, knowledge, subjective beliefs,
\end{abstract}

\section{INTRODUCTION}

Tobacco use remains the number one preventable cause of death, and a high priority of the Saudi Ministry of Health $^{1}$. Diseases such as lung cancer, heart diseases, and poor prognosis of COVID-19 can be prevented by tobacco cessation. Scientists have emphasized that smoking cessation should be encouraged especially during the COVID-19 pandemic ${ }^{2}$. It was also established that lung cancer is among the deadly diseases, in which more than $85 \%$ of incidents are due to tobacco smoking ${ }^{3}$. In the Kingdom of Saudi Arabia normative beliefs, control beliefs, and intentions to provide tobacco cessation services. Constructs were measured with latent variables, and associations were estimated in a structural equation path model.

RESULTS The majority (71\%) of physicians reported minimal or no training on tobacco cessation. The average score for tobacco treatment knowledge was 4.09 out of 10 questions. On a scale of 1 to 5 , the mean score for intention to provide tobacco cessation services was 3.26. Mean scores for subjective, normative, and control beliefs were $3.45,3.41$, and 3.43, respectively. Mean score for self-efficacy was 3.38. Self-efficacy had a strong influence on intention to provide cessation services via several pathways.

CONCLUSIONS Due to lack of prior training among physicians, we recommend delivering future tobacco cessation training. Such training would be effective, given that scores on selfefficacy, beliefs, and intentions, in this study indicate a promising attitude toward the provision of tobacco cessation services.

(KSA) in 2014, lung cancer ranked among the top four diseases affecting the male population, and ranked 17 th among females ${ }^{4}$. Other forms of cancer, such as polycythemia, as well as cardiovascular diseases and chronic obstructive pulmonary disease, were also associated with smoking ${ }^{5-7}$. Seventy thousand Saudis die each year due to smokingrelated diseases ${ }^{8}$. There is strong evidence from research that quitting smoking produces substantial health benefits including a large reduction in lung cancer incidence ${ }^{9}$. Heart disease is another important consequence of tobacco use $\mathrm{e}^{10}$. 
The average age of patients with heart failure in KSA is almost 10 years younger than in developed countries ${ }^{11}$ and they also have a much higher prevalence of diabetes.

The Kingdom of Saudi Arabia (KSA) has long been making significant efforts to combat the high prevalence of tobacco use among its population. The Saudi Ministry of Health joined the Health Organization Framework Convention for Tobacco Control in 2005, which led to the signature of the WHO Framework Convention on Tobacco Control (FCTC) ${ }^{12}$. Subsequently, smoking was banned in public places, fines were imposed, and warnings on tobacco packages were mandated ${ }^{1}$. Despite strong efforts, and due to the strong addictive properties of nicotine, the prevalence of tobacco use in KSA is $12.2 \%$, with a much higher use among males $(23.7 \%)$ and an unacceptably high prevalence among youth $(14.9 \%)^{13}$. Tobacco use in KSA is not limited to cigarettes; other tobacco forms, such as smokeless tobacco $(29.7 \%)^{14}$ and waterpipes $(24.2 \%)^{15}$, are also highly prevalent. The use of electronic nicotine delivery system (ENDS) is also prevalent in KSA, especially among students ${ }^{16,17}$. The current practice of smoking cessation counseling by a healthcare provider in KSA is less than optimal ${ }^{18}$. There is an urgent need to educate the population about the dangers of tobacco use and assist them to quit; however, a first step should be training and educating the healthcare professionals who will then provide tobacco prevention and cessation education to the population. To be able to effectively and efficiently train health professionals, we should first assess their baseline selfefficacy, knowledge, beliefs, and intentions to provide tobacco cessation counseling as well as the relationships among these.
However, our knowledge about physicians' current beliefs about tobacco cessation services in KSA is limited.

Studies pertaining to social and behavioral science indicate that professionals' self-efficacy and beliefs predict their intentions to provide tobacco cessation interventions in their practices (Figure 1) ${ }^{19}$. Those beliefs comprise three types: 1) subjective beliefs, i.e. the attitude of the health professional towards providing tobacco cessation services; 2) normative beliefs, i.e. what health professionals think of their colleagues' behavior and practices with regard to providing tobacco cessation services; and 3) control beliefs, i.e. the health professionals' perceived level of control over patients' behavior with regard to tobacco prevention, use and cessation.

Demographics, self-efficacy, knowledge and the three types of beliefs are hypothesized to influence health professionals' intentions to provide tobacco cessation interventions. Intentions predict actual behavioral outcomes, i.e. provision of tobacco cessation services to patients ${ }^{19}$. Therefore, the aim of this study is to assess the seven constructs (demographics, self-efficacy, knowledge, subjective beliefs, normative beliefs, control beliefs, and intentions) hypothesized to influence the likelihood of providing tobacco cessation services.

\section{METHODS}

\section{Study design}

This study is questionnaire-based and of cross-sectional design. Participants were selected using a one-stage, stratified, and clustered sampling design.

Figure 1. Relationship of the seven constructs, guided by Theory of Reasoned Action framework, hypothesized to influence health professionals' likelihood to provide tobacco cessation services

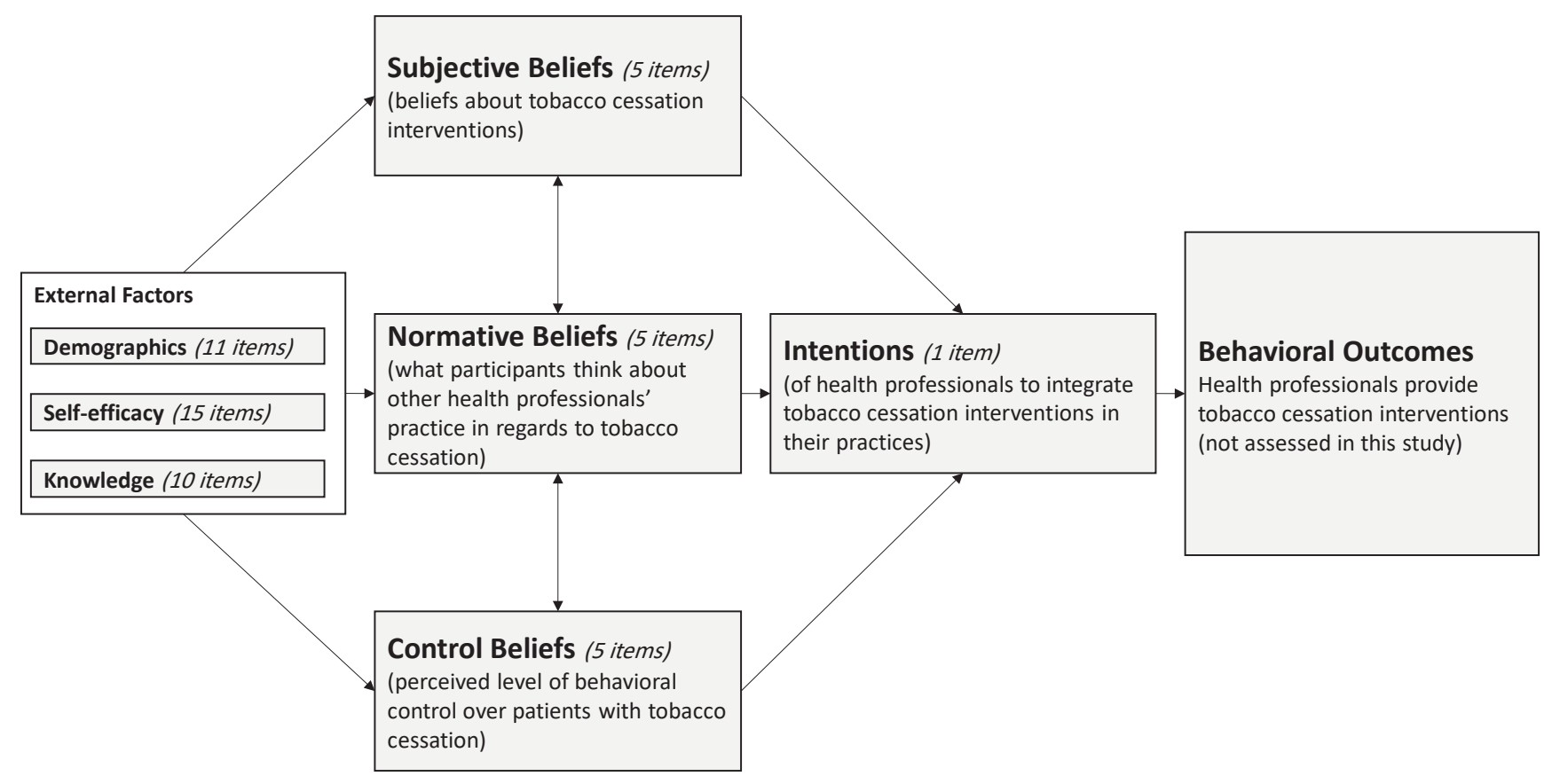




\section{Theoretical framework and instrument}

The Theory of Reasoned Action (TRA), originally developed by Fishbein ${ }^{19}$, was the guiding framework for the study (Figure 1). TRA is a general theory of human behavior that deals with the relations among knowledge, beliefs, intentions, and behavior. Scholars frequently use this theory to understand important behaviors such as cigarette smoking, alcohol consumption, marijuana use, and illicit drug use $^{20}$. Behavioral and cognitive self-report measures are the most commonly used modalities for data collection in social and behavioral science due to their feasibility, low cost, and efficiency ${ }^{21}$. Items in our instrument were adopted and slightly modified (to fit our study objective) from Hudmon et $\mathrm{al}^{22}$ and also from Amole et al. ${ }^{23}$. The instrument we adopted from Hudmon et al. ${ }^{22}$ was reviewed by nine experts and had acceptable psychometric properties as evident by its high reliability indicator (e.g. Cronbach alpha $=0.94$ for self-efficacy, 0.86 and 0.70 for beliefs). Our final instrument comprised a total of 52 items. Figure 1 shows the number of items mapped to each construct. Survey items are available in the Supplementary file.

\section{Setting}

Riyadh city is divided into five districts, Center, South, East, North, and West (Table 1). In each district there are several primary healthcare centers (PHCs) affiliated with the Ministry of Health (MOH). PHCs are located in most localities of the city and provide free-of-charge primary medical care services for the majority of residents without the need of referrals. Twenty percent of PHCs were randomly selected in this study.

\section{Participants}

All physicians in each of the selected PHCs were invited to participate in this study.

\section{Data and sample}

A list of all PHCs was obtained from the Department of Census in MOH. Cluster sampling was performed in which random samples $(20 \%$; $=25)$ of the PHCs in each district

Table 1. Total number of primary healthcare centers (PHCs) in each of the five districts, and the number of PHCs randomly selected to participate in this study

\begin{tabular}{l|c|c|}
$\begin{array}{l}\text { Districts in } \\
\text { Riyadh city }\end{array}$ & $\begin{array}{c}\text { Total number of } \\
\text { PHCs }\end{array}$ & $\begin{array}{c}\text { Number of PHCs } \\
\text { randomly selected } \\
\text { to participate }\end{array}$ \\
\hline Center & 17 & 4 \\
South & 16 & 4 \\
East & 30 & 6 \\
North & 28 & 6 \\
West & 23 & 5
\end{tabular}

were selected. All physicians in each of the selected PHCs were then invited to participate in this study. Psychometric experts have indicated that a sample of 200-300 individuals is optimal ${ }^{24,25}$. We therefore collected data until an adequate sample size was achieved.

\section{Data collection}

Data were collected using an anonymous self-administered questionnaire. Participants were asked by data collectors to insert the completed questionnaires in an anonymous box kept at a designated place in their respective departments to protect their identity and to ensure anonymity and confidentiality of the data. Data collectors left paper questionnaires on designated areas and returned to the location two to three days later to collect those completed and inserted in the box. Informed consent was included on the first page of the questionnaire on which potential participants would either accept or decline participation. Identity of participants was kept confidential. Data were then entered into an Excel sheet manually.

\section{Measures}

Demographics

Several self-reported demographic characteristics of the respondents were collected to be evaluated as covariates in the analysis. These included: age, gender, years in practice, whether or not they hold a specialty certification, current position in the PHC, name of PHC, the amount of tobacco cessation training previously received (extensive, moderate, minimal, none), whether or not they smoke, whether or not they have smoked 100 or more cigarettes in their lifetime, frequency of smoking $(0=$ non-smoker, $1=<5$ per day, $2=$ $5-9$ per day, $3=10-14$ per day, and $4=>14$ per day), and description of tobacco use, such as cigarettes, electronic cigarettes, cigars, pipes, shisha (use tobacco once or more a day, use tobacco less than once a day, used tobacco but now abstinent, experimented with tobacco a few times in the past).

\section{Self-efficacy}

This was measured using a latent variable with fifteen indicators from the self-efficacy scale constructed by Hudmon et al. ${ }^{22}$. An example item was: 'How do you rate your overall ability to help patients quit using tobacco?' with response options ranging: $1=$ poor to $5=$ excellent. The model fit for the self-efficacy latent variable was just adequate $\left[\chi^{2}=485.3\right.$ (86), $\mathrm{p}=0.000$; $\mathrm{CFI}=0.880$, TLI $=0.853$, RMSEA $=0.13]$.

\section{Knowledge}

This was assessed as a sum score of correct answers to a ten-question knowledge quiz derived from Amole et al. ${ }^{23}$. Two case studies describing patients wishing to quit smoking were presented followed by five questions about treatment options or nicotine addiction for each case, each of three 
types of beliefs: subjective, normative, and control, which were measured using latent variables with indicators from the Theory of Reasoned Action Theory ${ }^{19}$. Response options for subjective and normative belief indicators ranged: $1=$ not at all to $5=$ extremely. Response options for control belief indicators ranged: $1=$ none to $5=$ very high. Items asking about frequency ranged: $1=$ never to $5=$ always .

\section{Subjective beliefs}

This latent variable was measured with five observed indicators. An example item was: 'How important do you think it is to address tobacco cessation in your clinical practice?'. The subjective beliefs latent variable model fit was excellent $\left[\chi^{2}=7.7\right.$ (5), $p=0.18$; CFI $=0.996$, TLI $=0.992$, RMSEA $=0.04]$.

\section{Normative beliefs}

This latent variable was measured with five observed indicators. Indicators parallel the subjective beliefs items, but ask what the participant thinks other providers believe, e.g. 'How important do you think your provider colleagues think it is to address tobacco cessation in their clinical practice?'. The normative beliefs latent variable model fit was excellent $\left[\chi^{2}=4.0(5), p=0.83 ;\right.$ CFI $=1.00, T L I=1.00$, RMSEA $\left.=0.00\right]$.

\section{Control beliefs}

This latent variable was measured with five observed indicators. An example item was: 'How much influence do you think you have to help your clients/patients become tobacco free?'. The control beliefs latent variable model fit was excellent $\left[\chi^{2}=3.6(4), p=0.460 ; C F I=1.00, T L I=1.00\right.$, RMSEA=0.00].

\section{Intentions}

Intention to provide smoking cessation intervention was measured using a single item. The question asked was: 'Do you have intentions, within the next six weeks, to give/ recommend evidence-based interventions to help individuals quit using tobacco?'. Response options ranged: $1=$ not at all to $5=$ extremely.

\section{Data analyses}

A path model was estimated to test hypotheses within the Theory of Reasoned Action theoretical framework. Path models were estimated in a structural equation modeling framework using latent variables to measure constructs and simultaneous estimation of pathway equations ${ }^{26}$. All latent variables were evaluated and modified to maximize the fit to the data. Mediated effects were estimated using a productof-coefficients method ${ }^{27}$. Bootstrapping with 1000 replicates was used to obtain standard errors for the mediated effects. Direct maximum likelihood for missing data was used in order to retain observations with missing responses ${ }^{28}$. Table 2 indicates how many participants completed each item. Standard errors were corrected for district strata and for nesting of participants within PHCs. Mplus version 8.3 was used for all analyses.

\section{Model specification}

Prior to arriving at the final model, an initial model was estimated with all seven demographic covariates described above and all possible pathways indicated by the theoretical model shown in Figure 1. Covariates with no statistically significant pathways (alpha $>0.05$ ) were removed from the model. Only age and prior training of the respondents had significant associations and remained in the model. Pathways that were not statistically significant (alpha $>0.05$ ) for the remaining variables were removed. This resulted in the parsed model presented in Figure 2. Although not depicted in Figure 2, age and prior training were allowed to correlate. Knowledge and self-efficacy residuals were also correlated, and the three belief-type residuals were correlated with each other as is standard specification. The final model depicted in Figure 2 had acceptable model fit $\left[\chi^{2}=1364.1\right.$ (512), $p=0.000$; $\mathrm{CFI}=0.868$, TLI $=0.855$, RMSEA $=0.08]$. Estimates from this final, best fitting, path model are presented and interpreted.

\section{RESULTS}

\section{Participants}

A total of 291 practitioners completed the questionnaire. The sample comprises 174 (62\%) medical residents, 66 (24\%) board certified physicians, and $37(13 \%)$ consultants in Riyadh city. The average age of respondents was 40 years with an average of 13 years in practice. Forty-nine percent of respondents were female and $15 \%$ were current smokers. More than a third of the respondents (38\%) reported no

Table 2. Descriptive statistics for model variables $(\mathrm{N}=291)$

\begin{tabular}{lccccc} 
& n & $\begin{array}{c}\text { Mean/ } \\
\text { proportion }\end{array}$ & $\begin{array}{c}\text { Standard } \\
\text { deviation }\end{array}$ & Range \\
\hline Outcome & & & & \\
Intentions & 290 & 3.26 & 1.15 & $1-5$ \\
\hline Mediators & & & & \\
\hline Subjective beliefs & 291 & 3.45 & 0.72 & $1-5$ \\
Normative beliefs & 291 & 3.41 & 0.68 & $1-5$ \\
Control beliefs & 291 & 3.43 & 0.69 & $1-5$ \\
Covariates & & & & \\
Self-efficacy & 291 & 3.38 & 0.66 & $1-5$ \\
Knowledge score & 291 & 4.05 & 1.64 & $0-10$ \\
Age (years) & 288 & 40 & 8.7 & $23-65$ \\
Female & 291 & 0.49 & 0.50 & $0-1$ \\
Years in practice & 276 & 13 & 8.3 & $1-40$ \\
Prior training & 290 & 1.9 & 0.85 & $1-4$ \\
$\begin{array}{l}\text { Daily smoking } \\
\text { frequency }\end{array}$ & 288 & 0.40 & 1.07 & $0-5$ \\
& & & &
\end{tabular}




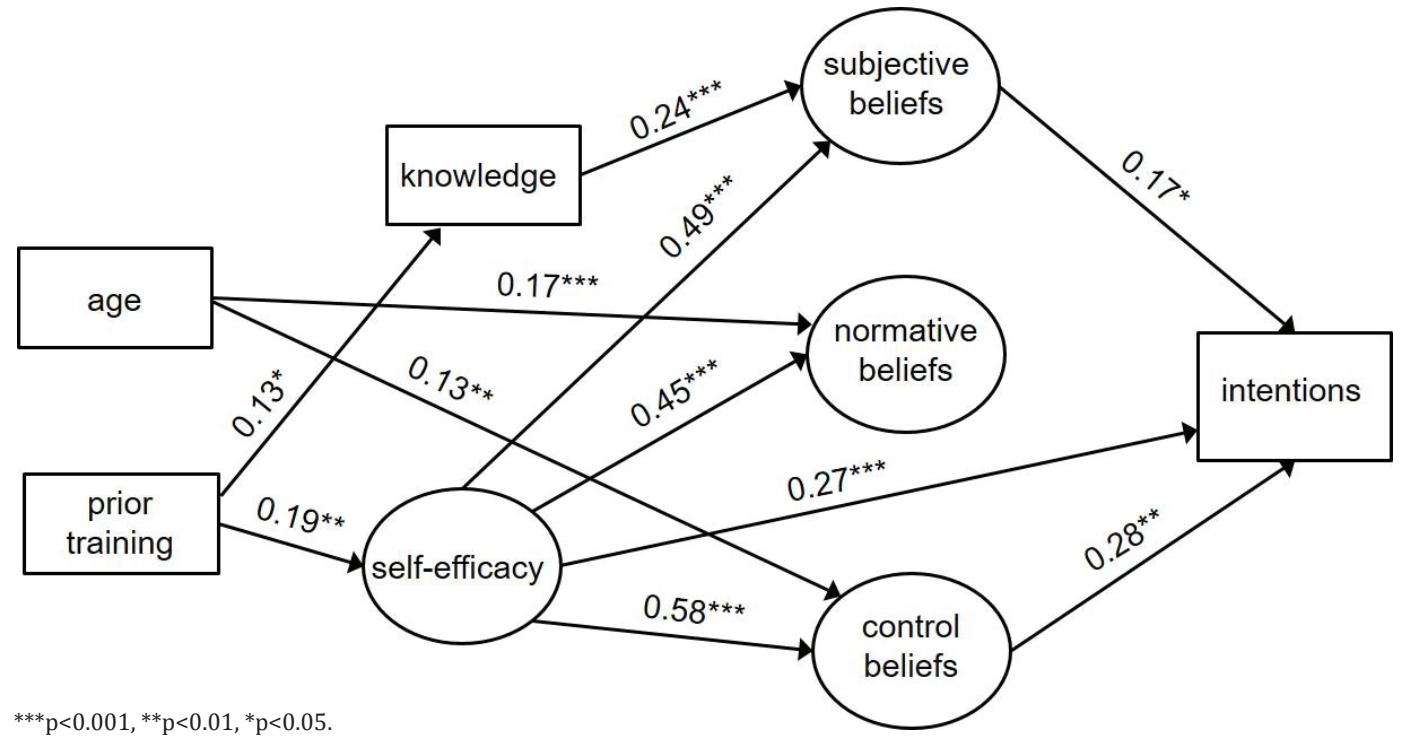

previous tobacco cessation training, 33\% reported minimal training, $27 \%$ reported moderate training, and $2 \%$ reported extensive training.

Statistical description of model variables is provided in Table 2. The average value for intention to provide or recommend tobacco cessation interventions was 3.26 , a little above moderate on a 1 to 5 scale. In all, $14.8 \%$ of the participants selected 'extremely' for intentions; $29.3 \%$ selected 'very'; $31.4 \%$ selected 'moderately'; $15.9 \%$ selected 'slightly'; and 8.6\% selected 'not at all'. The means of the subjective, normative, and control belief latent variables were: $3.45,3.41$, and 3.43 , respectively; averaging between 'moderately' and 'very' or 'moderate' and 'high' on the 1 to 5 scale. Correlations among the three belief variables ranged from 0.72 to 0.75 (Table 3). Subjective, normative, and control beliefs were all correlated with intentions $(r=0.50$,
0.44 , and 0.56 , respectively). Average self-efficacy was 3.38 on a 1 to 5 scale, indicating a response averaging above 'good'. Self-efficacy was moderately correlated with all three belief types $(0.45<r<0.59)$ and with intentions $(r=0.51)$. Average knowledge score was four correct responses out of a possible ten. Knowledge score was associated weakly with subjective beliefs $(\mathrm{r}=0.19)$ and prior training $(\mathrm{r}=0.13)$. Prior training was also weakly associated with intentions $(\mathrm{r}=0.17)$, subjective beliefs ( $\mathrm{r}=0.14)$, control beliefs $(\mathrm{r}=0.14)$, and selfefficacy $(\mathrm{r}=0.19)$.

The final, most parsimonious path model with standardized coefficient estimates is portrayed in Figure 2. After controlling for subjective beliefs, control beliefs, and self-efficacy, normative beliefs did not associate with intentions. On the other hand, both subjective and control beliefs were positively associated with intentions. For every

Table 3. Correlations among model variables*

\begin{tabular}{|c|c|c|c|c|c|c|c|c|c|c|}
\hline Variables & INT & SB & NB & CB & SE & KS & A & YP & PT & SF \\
\hline Intentions (INT) & - & & & & & & & & & \\
\hline Subjective beliefs (SB) & 0.50 & - & & & & & & & & \\
\hline Normative beliefs (NB) & 0.44 & 0.74 & - & & & & & & & \\
\hline Control beliefs (CB) & 0.56 & 0.72 & 0.75 & - & & & & & & \\
\hline Self-efficacy (SE) & 0.51 & 0.47 & 0.46 & 0.58 & - & & & & & \\
\hline Knowledge score (KS) & 0.00 & 0.19 & -0.07 & 0.01 & -0.09 & - & & & & \\
\hline Age $(A)$ & 0.07 & 0.07 & 0.21 & 0.18 & 0.06 & 0.10 & - & & & \\
\hline Years in practice (YP) & 0.05 & 0.05 & 0.12 & 0.12 & 0.01 & 0.08 & 0.88 & - & & \\
\hline Prior training (PT) & 0.17 & 0.14 & 0.08 & 0.14 & 0.19 & 0.13 & -0.04 & -0.04 & - & \\
\hline Smoking frequency (SF) & -0.02 & -0.03 & -0.02 & -0.06 & 0.03 & -0.08 & -0.06 & -0.03 & 0.13 & - \\
\hline
\end{tabular}

*Categorical variable gender excluded. Bold indicates statistically significant correlation with $\mathrm{p}<0.05$. 
Table 4. Parameter estimates for direct and total effects ( $N=291)$

$\begin{array}{lcc}\text { Direct effects } & \mathbf{b}^{\mathrm{a}} & \mathbf{9 5 \%} \text { CI } \\ \text { subjective beliefs } \rightarrow \text { intentions } & 0.27 & (0.01-0.52) \\ \text { control beliefs } \rightarrow \text { intentions } & 0.47 & (0.09-0.85) \\ \text { self-efficacy } \rightarrow \text { subjective beliefs } & 0.53 & (0.35-0.72) \\ \text { self-efficacy } \rightarrow \text { normative beliefs } & 0.46 & (0.27-0.65) \\ \text { self-efficacy } \rightarrow \text { control beliefs } & 0.59 & (0.45-0.74) \\ \text { self-efficacy } \rightarrow \text { intentions } & 0.47 & (0.19-0.74) \\ \text { knowledge } \rightarrow \text { subjective beliefs } & 0.11 & (0.06-0.15) \\ \text { age in years } \rightarrow \text { normative beliefs } & 0.01 & (0.01-0.02) \\ \text { age in years } \rightarrow \text { control beliefs } & 0.01 & (0.00-0.02) \\ \text { prior training } \rightarrow \text { knowledge } & 0.25 & (0.02-0.48) \\ \text { prior training } \rightarrow \text { self-efficacy } & 0.15 & (0.05-0.25) \\ \text { Total effects* } & \mathbf{b} & 95 \% \text { CI } \\ \text { self-efficacy } \rightarrow \text { intentions } & 0.89 & (0.70-1.08) \\ \text { prior training } \rightarrow \text { intentions } & 0.14 & (0.05-0.23)\end{array}$

*Bootstrap standard errors were used for total effects. a Coefficient b: represents regression coefficient estimates.

\section{Table 5. Parameter estimates for indirect effects} $(\mathrm{N}=291)$

\begin{tabular}{lcc}
\hline Indirect effects* & $\mathbf{b}^{\mathrm{a}}$ & $95 \% \mathrm{CI}$ \\
\hline $\begin{array}{l}\text { self-efficacy } \rightarrow \text { subjective beliefs } \rightarrow \text { intentions } \\
\text { self-efficacy } \rightarrow \text { control beliefs } \rightarrow \text { intentions }\end{array}$ & 0.14 & $(-0.02-0.30)$ \\
$\begin{array}{l}\text { knowledge } \rightarrow \text { subjective beliefs } \rightarrow \text { intentions } \\
\text { age in years } \rightarrow \text { control beliefs } \rightarrow\end{array}$ & 0.03 & $(0.04-0.52)$ \\
$\begin{array}{l}\text { intentions } \\
\text { prior training } \rightarrow \text { self-efficacy } \rightarrow \text { intentions }\end{array}$ & 0.01 & $(0.00-0.06)$ \\
$\begin{array}{l}\text { prior training } \rightarrow \text { knowledge } \rightarrow \text { subjective } \\
\text { beliefs } \rightarrow \text { intentions }\end{array}$ & 0.01 & $(0.01-0.13)$ \\
$\begin{array}{l}\text { prior training } \rightarrow \text { self-efficacy } \rightarrow \text { subjective } \\
\text { beliefs } \rightarrow \text { intentions }\end{array}$ & 0.02 & $(-0.01-0.02)$ \\
$\begin{array}{l}\text { prior training } \rightarrow \text { self-efficacy } \rightarrow \text { control } \\
\text { beliefs } \rightarrow \text { intentions }\end{array}$ & 0.04 & $(0.00-0.09)$ \\
& &
\end{tabular}

*Bootstrap standard errors were used for total effects. a Coefficient b: represents regression coefficient estimates.

unit higher subjective belief value, there was an associated 0.27 point higher level of intentions. Table 4 provides the unstandardized estimates for the model. For every unit higher control belief value, there was an associated 0.47 point higher level of intentions. Self-efficacy was similarly directly associated with intentions $(b=0.47)$. The strongest associations in the model were the effects of self-efficacy on the beliefs. A unit higher self-efficacy value was associated with $0.53,0.46$, and 0.59 higher subjective, normative, and control beliefs value, respectively (Table 4), while knowledge only affected subjective beliefs $(b=0.11)$. Age of the respondent was positively corelated to both normative and control beliefs ( $\mathrm{b}=0.01$ for both), indicating that being 10 years older was associated with a 0.10 higher normative and control beliefs average. Prior training was associated with knowledge score $(b=0.25)$ and self-efficacy $(b=0.15)$. Direct effects in Figure 2 are given in standardized units.

As shown in Figure 2, several variables indirectly affected intentions to provide or recommend smoking cessation interventions. Self-efficacy affected intentions directly, but also indirectly through subjective beliefs and control beliefs. These indirect estimates are provided in Table 5. Mostly, self-efficacy indirectly related to intentions through control beliefs. A unit higher self-efficacy value was associated with 0.28 higher intentions $\left(b_{\text {std }}=0.16\right)$ due to the increase in control beliefs, and $0.14\left(b_{\text {std }}=0.08\right)$ higher intentions due to the increase in subjective beliefs. Combining both the direct effect and indirect effects together, self-efficacy had a very strong influence on intentions. The total effect of self-efficacy was 0.89 (Table 4) and the standardized total effect was 0.51 . Knowledge score only affected intentions indirectly through subjective beliefs $\left(\mathrm{b}=0.03 ; \mathrm{b}_{\text {std }}=0.04\right)$ (Table 5 ).

Prior training in tobacco cessation impacted intentions through many pathways, albeit of small effect (Figure 2 and Table 5). The largest indirect effect of prior training was through self-efficacy. A unit higher level of training was associated with a $0.07\left(b_{\text {std }}=0.05\right)$ higher level of intentions due to the influence of training on self-efficacy. The second strongest indirect pathway was from prior training to selfefficacy to control beliefs to intentions $\left(b=0.04 ; b_{\text {std }}=0.03\right)$. The overall, total effect of prior training on intentions through all indirect pathways was $0.14\left(\mathrm{~b}_{\mathrm{std}}=0.10\right.$; Table 4). This indicates that a unit higher level of prior training is associated with 0.14 higher intention through all mechanisms.

\section{DISCUSSION}

The results of this study are an important contribution to the literature due to the scarcity of such knowledge about the beliefs and intentions of physicians in KSA. The large sample size, the framework we selected to guide the study, and the acceptable psychometric properties of items used in our instrument, further strengthen our study methodology. The instrument validated in this study could be used to administer future pre- and post-training assessments to evaluate training effectiveness.

Our study shows that self-efficacy had a very strong influence on intention to provide tobacco cessation services via several pathways. According to the Theory of Reasoned Action (TRA), intention predicts actual change in behavior, i.e. providing smoking cessation services to patients (Figure 
1). Self-efficacy can be improved by training as established by prior studies from several countries assessing a wide-range of health professions ${ }^{29-32}$. It is therefore expected that similar positive effects would be attained in KSA health professions.

Our study mirrors previous findings in the literature. A study in 2014 assessed knowledge of tobacco use and treatment among medical students in Saudi Arabia, and found them to be inadequately trained. The authors recommended prioritizing tobacco cessation training and including this important topic in medical education curricula $^{33}$. Our study confirmed the less than ideal knowledge of tobacco use and cessation among physicians (average score 4.05/10), however, it shows promising positive beliefs and willingness of physicians to implement services (beliefs and intentions averaging above moderate). In our study, $15 \%$ of physicians were current smokers, higher than the national average $(12.2 \%)^{13}$, but slightly less than the prevalence among healthcare professionals found in the western region of KSA in $2015(18.4 \%)^{34}$. Another study assessed attitudes of surgeons practicing in KSA toward preoperative smoking cessation, and found that more than $70 \%$ of patients would like to quit smoking after surgery ${ }^{35}$. Almost $70 \%$ of surgeons reported that their patients quit before the surgery, however, $58.8 \%$ of patients reported not receiving advice to quit. Authors emphasized the importance of training surgeons on the negative effects of smoking on surgery outcomes ${ }^{35}$. Compared to the tobacco prevalence in other countries, prevalence in KSA is lower than the worldwide average (25.0\%), however, it is higher than many countries that have made progress in tobacco cessation ${ }^{36}$. Our findings along with previous studies reinforce the critical need to provide tobacco cessation training to all KSA healthcare professionals.

\section{Strengths and limitations}

An important limitation of this study is the inherent inferiority of self-reported opinions compared to objective measurements. Being a cross-sectional study limits our knowledge of changes in service provision over a period of time. Another limitation is the length of survey, having 52 items may have caused a burden on participants. Additionally, being paper based, we were unable to capture time taken to complete the survey. Data collection was performed until sample size was adequate to provide stable psychometric analysis, however, total number of physicians in each center was not documented due to the many changes occurring in short periods of time (e.g. physicians leaving the practice, physicians moving from center to center, or new hires). Despite these limitations, our study adds important and timely information. The results will inform future steps and plans especially with regard to educational interventions in KSA, such as training workshops. Training healthcare professionals on this important epidemic is critical, and can be accomplished online as well as in live workshops, if safe and practical. Counseling tobacco users by a trained professional has been shown to be effective in increasing the rate of quitting tobacco ${ }^{37}$. Additionally, patients perceive health professionals to be a trustworthy and reliable source for tobacco cessation information ${ }^{38}$. Trained professionals will be able to apply the knowledge in a variety of settings such as inpatient, outpatient, and clinics. Many previous studies have shown that training health professionals on tobacco cessation significantly increased their selfefficacy ${ }^{29,39-42}$. Such training endeavors are thereby expected to positively influence all the other pathways to improve the intended behavioral outcome (i.e. provide tobacco cessation services). Therefore, we will use the results of this study to develop and evaluate future training programs for health professionals in KSA.

\section{CONCLUSIONS}

The majority of physicians practicing in KSA reported minimal or no training on tobacco cessation indicating a critical need for developing and implementing tobacco cessation training programs. Physicians exhibited less than optimal knowledge about tobacco cessation and nicotine dependence. However, their self-reported self-efficacy, beliefs, and intentions to provide tobacco cessation services were promising, with average score of above 3 on a scale of 1 to 5. Because self-efficacy was shown to improve intentions to provide tobacco cessation services via several pathways, and thereby improve actual provision of such services, we recommend and emphasize the importance of providing smoking cessation training to physicians practicing in KSA. Every effort should be made to prevent tobacco use and assist tobacco users to quit.

\section{REFERENCES}

1. Al-Munif M. Report on tobacco control program of Ministry of Health in Saudi Arabia. Ministry of Health Tobacco Control Program; 2009.

2. Berlin I, Thomas D, Le Faou AL, Cornuz J. COVID-19 and Smoking. Nicotine Tob Res. 2020;22(9):1650-1652. doi:10.1093/ntr/ntaa059

3. Warren GW, Cummings KM. Tobacco and lung cancer: risks, trends, and outcomes in patients with cancer. Am Soc Clin Oncol Educ Book. 2013;359-364. doi:10.14694/EdBook_AM.2013.33.359

4. Saudi Health Council. Cancer Incidence Report: Saudi Arabia 2014. Kingdom of Saudi Arabia, Saudi Health Council, Saudi Cancer Registry. Accessed March 18, 2021. https://www. nhic.gov.sa/eServices/Documents/2014.pdf

5. Alkhedaide AQ. Tobacco smoking causes secondary polycythemia and a mild leukocytosis among heavy smokers in Taif City in Saudi Arabia. Saudi J Biol Sci. 2020;27(1):407411. doi:10.1016/j.sjbs.2019.11.001

6. Idrees M, Koniski ML, Taright S, et al. Management of chronic obstructive pulmonary disease in the Middle East and North Africa: results of the BREATHE study. Respir Med. 2012;106(Suppl 2):S33-S44. doi:10.1016/S0954-6111(12)70013-6

7. Altaleb FF, Alshammari OM, Alanazi HM, et al. Pattern and 
factors associated with cardiovascular diseases among patients attending the cardiac center in Arar City, Northern Saudi Arabia. Electron Physician. 2017;9(10):5459-5464. doi:10.19082/5459

8. Hassan R. Saudi Health Ministry in deal to combat smoking. August 22, 2017. Accessed March 11, 2021. https://www. arabnews.com/node/1148741/saudi-arabia

9. Fagerström K. The epidemiology of smoking: health consequences and benefits of cessation. Drugs. 2002;62(Suppl 2):1-9. doi:10.2165/00003495-200262002-00001

10.U.S. Department of Health and Human Services. Smoking Cessation: A Report of the Surgeon General. U.S. Department of Health and Human Services, Centers for Disease Control and Prevention, National Center for Chronic Disease Prevention and Health Promotion, Office on Smoking and Health; 2020. Accessed March 18, 2021. https://www.hhs. gov/sites/default/files/2020-cessation-sgr-full-report.pdf

11.AlHabib KF, Elasfar AA, AlBackr H, et al. Design and preliminary results of the heart function assessment registry trial in Saudi Arabia (HEARTS) in patients with acute and chronic heart failure. Eur J Heart Fail. 2011;13(11):11781184. doi:10.1093/eurjhf/hfr111

12. Awan KH, Hussain QA, Khan S, et al. Accomplishments and challenges in tobacco control endeavors - Report from the Gulf Cooperation Council countries. Saudi Dent J. 2018;30(1):13-18. doi:10.1016/j.sdentj.2017.08.003

13. Moradi-Lakeh M, El Bcheraoui C, Tuffaha M, et al. Tobacco consumption in the Kingdom of Saudi Arabia, 2013: findings from a national survey. BMC Public Health. 2015;15:611. doi:10.1186/s12889-015-1902-3

14. Alrashidi AG, Alrashidi TG, Alrashedi SA, et al. Epidemiologic Pattern and Types of Oral Smokeless Tobacco Usage in Saudi Arabia. J Contemp Dent Pract. 2018;19(4):456-462. doi:10.5005/jp-journals-10024-2283

15. Daradka H, Khabour O, Alzoubi K, Nakkash R, Eissenberg T. Tobacco and waterpipe use among university students in Saudi Arabia: impact of tobacco sales ban. East Mediterr Health J. 2019;25(2):111-118. doi:10.26719/emhj.18.021

16. Habib E, Helaly M, Elshaer A, et al. Prevalence and perceptions of e-cigarette use among medical students in a Saudi University. J Family Med Prim Care. 2020;9(6):30703075. doi:10.4103/jfmpc.jfmpc_235_20

17. Qanash S, Alemam S, Mahdi E, Softah J, Touman AA, Alsulami A. Electronic cigarette among health science students in Saudi Arabia. Ann Thorac Med. 2019;14(1):56-62. doi:10.4103/atm.ATM_76_18

18. Al-Jdani S, Mashabi S, Alsaywid B, Zahrani A. Smoking cessation counseling: Knowledge, attitude and practices of primary healthcare providers at National Guard Primary Healthcare Centers, Western Region, Saudi Arabia. J Family Community Med. 2018;25(3):175-182. doi:10.4103/jfcm.JFCM_142_17

19. Fishbein M. A theory of reasoned action: some applications and implications. Nebr Symp Motiv. 1980;27:65-116.

20. Fishbein M, Middlestadt SE. Using the theory of reasoned action to develop educational interventions: Applications to illicit drug use. Health Educ Res. 1987;2(4):361-371. doi:10.1093/her/2.4.361

21. Whitley BE, Kite ME. Principles of Research in Behavioral Science. 3rd ed. Routledge; 2012.

22. Hudmon KS, Prokhorov AV, Corelli RL. Tobacco cessation counseling: pharmacists' opinions and practices. Patient Educ Couns. 2006;61(1):152-160. doi:10.1016/j.pec.2005.03.009

23. Amole J, Heath J, Joshua TV, McLear B. Online tobacco cessation education to optimize standards of practice for psychiatric mental health nurses. Nurs Clin North Am. 2012;47(1):71-79. doi:10.1016/j.cnur.2011.10.006

24. Nunnally JC. Psychometric theory. 2nd ed. McGraw-Hill; 1978.

25. DeVellis RF. Scale development: Theory and applications. Vol 26. 4th ed. Sage Publications; 2016.

26. Bollen KA. Structural Equations with Latent Variables. Wiley; 1989.

27. MacKinnon DP, Fairchild AJ, Fritz MS. Mediation analysis. Annu Rev Psychol. 2007;58:593-614. doi:10.1146/annurev.psych.58.110405.085542

28. Arbuckle JL. Full information estimation in the presence of incomplete data. In: Marcoulides GA, Schumacker RE, eds. Advanced structural equation modeling: Issues and techniques. Lawrence Erlbaum Associates; 1996:243-277.

29. Corelli RL, Kroon LA, Chung EP, et al. Statewide evaluation of a tobacco cessation curriculum for pharmacy students. Prev Med. 2005;40(6):888-895. doi:10.1016/j.ypmed.2004.10.003

30. Schwindt R, McNelis AM, Agley J, Hudmon KS, Lay K, Wilgenbusch B. Training future clinicians: An interprofessional approach to treating tobacco use and dependence. J Interprof Care. 2019;33(2):200-208. doi:10.1080/13561820.2018.1534808

31.Zhang CM, Xiao D, West R, et al. Evaluation of 3-day smoking cessation training course for doctors from 38 cities in China. Chin Med J (Engl). 2012;125(7):1338-1340. doi:10.3760/cma.j.issn.0366-6999.2012.07.026

32.Garg A, Serwint JR, Higman S, et al. Self-efficacy for smoking cessation counseling parents in primary care: an office-based intervention for pediatricians and family physicians. Clin Pediatr (Phila). 2007;46(3):252-257. doi:10.1177/0009922806290694

33. Jradi H, Al-Shehri A. Knowledge about tobacco smoking among medical students in Saudi Arabia: findings from three medical schools. J Epidemiol Glob Health. 2014;4(4):269276. doi:10.1016/j.jegh.2014.04.001

34. Mahdi HA, Elmorsy SA, Melebari LA, et al. Prevalence and intensity of smoking among healthcare workers and their attitude and behavior towards smoking cessation in the western region of Saudi Arabia: A Cross-sectional study. Tob Prev Cessat. 2018;4(August):1-8. doi:10.18332/tpc/93787

35. Hajjar WM, Al-Nassar SA, Alahmadi RM, Almohanna SM, Alhilali SM. Behavior, knowledge, and attitude of surgeons and patients toward preoperative smoking cessation. Ann Thorac Med. 2016;11(2):132-140. doi:10.4103/1817-1737.180021

36. GBD 2015 Tobacco Collaborators. Smoking prevalence and attributable disease burden in 195 countries and territories, 1990-2015: a systematic analysis from the Global Burden of 
Disease Study 2015. Lancet. 2017;389(10082):1885-1906. doi:10.1016/S0140-6736(17)30819-X

37.U. S. Department of Health and Human Services. Treating Tobacco Use and Dependence. Quick reference guide for clinicians, 2008 update. U.S. Department of Health and Human Services, Public Health Service; 2009. Accessed March 18, 2021. https://www.healthquality.va.gov/tuc/ phs_2008_quickguide.pdf

38. Halladay JR, Vu M, Ripley-Moffitt C, Gupta SK, O'Meara C, Goldstein AO. Patient Perspectives on Tobacco Use Treatment in Primary Care. Prev Chronic Dis. 2015;12:140408. doi:10.5888/pcd12.140408

39. Kristina SA, Thavorncharoensap M, Pongcharoensuk P, Prabandari YS. Impact of smoking cessation training for community pharmacists in Indonesia. Asian Pac J Cancer Prev. 2015;16(8):3319-3323. doi:10.7314/apjcp.2015.16.8.3319

40. Singleton JA, Carrico RM, Myers JA, Scott DA, Wilson RW, Worth CT. Tobacco cessation treatment education for dental students using standardized patients. J Dent Educ. 2014;78(6):895-905. doi:/10.1002/j.0022-0337.2014.78.6.tb05743.x

41. Martin BA, Bruskiewitz RH, Chewning BA. Effect of a tobacco cessation continuing professional education program on pharmacists' confidence, skills, and practice-change behaviors. J Am Pharm Assoc (2003). 2010;50(1):9-16. doi:10.1331/JAPhA.2010.09034

42. Leong SL, Lewis PR, Curry WJ, Gingrich DL. Tobacco world: evaluation of a tobacco cessation training program for third-year medical students. Acad Med. 2008;83(Suppl 10):S25-S28. doi:10.1097/ACM.0b013e318183e271

CONFLICTS OF INTEREST

The authors have each completed and submitted an ICMJE form for disclosure of potential conflicts of interest. The authors declare that they have no competing interests, financial or otherwise, related to the current work. H. M. Alsaran, Y. E. Bashawri and N. Elkhadragy report grants from King Fahad Medical City Research Center, Department of Biomedical Research Administration. N. Elkhadragy also reports consulting fees from another funding agency.

FUNDING

This work was supported by King Fahad Medical City Research Center,
Department of Biomedical Research Administration (Proposal number: 18-465).

\section{ETHICAL APPROVAL AND INFORMED CONSENT}

Ethical approval was obtained from the King Fahad Medical City, Riyadh, Saudi Arabia. Informed consent was included on the questionnaire on which potential participants would either accept or decline participation. The identity of participants was kept confidential.

PROVENANCE AND PEER REVIEW

Not commissioned; externally peer reviewed. 